\title{
"Marielle virou semente": representatividade e os novos modos de interação política da mulher negra nos espaços institucionais de poder
}

Andéa Franco Lima e Silva ${ }^{1}$

\section{RESUMO}

O presente artigo busca identificar as candidaturas de mulheres negras nas eleições proporcionais de 2018 como parte de um projeto coletivo, amplo e contínuo de emancipação e transformação social que tem orientado as experiências de organização e de resistência das mulheres negras desde o período da escravidão, até os atuais movimentos feministas negros. A partir dessa premissa, nos propomos a realizar uma breve revisão bibliográfica da literatura sobre o feminismo negro pra então conhecer, elencar e interpretar, a partir dessa revisão, as ações de campanha de candidatas negras aos pleitos proporcionais em 2018 que aderiram a uma proposta de coletivização dos mandatos. Nesse sentido, a morte violenta e prematura da vereadora Marielle Franco é vista, ao mesmo tempo, como tentativa de interrupção brusca desse projeto, e como gérmen de uma ação político-institucional inovadora, que preza pela participação coletiva, pela identidade racial e de gênero e pela ruptura com as formas tradicionais do fazer político.

Palavras-chave: Feminismo negro; Mulher negra; Representatividade política.

\section{ABSTRACT}

${ }^{1}$ Doutoranda no Programa de Pós-Graduação em Sociologia da UFPB. E-mail: cadastros.andrea@gmail.com. O presente trabalho foi realizado com apoio da Coordenação de Aperfeiçoamento de Pessoal de Nível Superior-Brasil (CAPES)-Código de Financiamento oo1. 
The present paper seeks to identify the candidacies of black women in the proportional elections of 2018 as part of a collective, broad and continuous project of emancipation and social transformation that has guided the experiences of organization and resistance of black women from the period of slavery to the current black feminist movements. Based on this premise, we propose to carry out a brief bibliographical review of the literature on black feminism in order to acknowledge, to list , and to understand the campaign actions of black candidates to the proportional elections in 2018, which have adhered to a proposal of collectivization of mandates. In this sense, the violent and premature death of councilwoman Marielle Franco is seen at the same time as an attempt to abruptly interrupt this project, and as the germ of an innovative political-institutional action, which values collective participation, racial identity and and the rupture with the traditional forms of political acting.

Keywords: Black feminism; Black woman; Political representativeness.

You may shoot me with your words, You may cut me with your eyes, You may kill me with your hatefulness, But still, like air, I'll rise.

(MAYA ANGELOU, 1978)

$\mathrm{M}$ arielle Franco, ${ }^{2}$ vereadora municipal do Rio de Janeiro, pelo Partido Socialismo e Liberdade - PSOL, e presidente da Comissão da Mulher na Câmara Municipal, sofreu um atentado na região central da cidade e foi assassinada no dia 14 de março de 2018. O carro que transportava a vereadora, sua assessora ${ }^{3}$ Fernanda Chavez, e seu motorista, Anderson Gomes, foi alvo de treze tiros. Quatro deles acertaram a cabeça da vereadora.

\footnotetext{
${ }^{2}$ Para mais informações sobre a biografia e trabalho de Marielle Franco, vide https://www.mariellefranco.com.br/

${ }^{3}$ A assessora de Marielle foi a única sobrevivente do atentado.
} 
Marielle nasceu em 1979, no Complexo da Maré, aglomerado urbano localizado na zona norte do Rio de Janeiro. Começou a trabalhar aos 11 anos para ajudar a família. Sua militância em Direitos Humanos se deu aos 18 anos, em 1998, quando uma de suas melhores amigas foi mais uma vítima fatal de uma bala perdida em um confronto entre policiais e traficantes da Maré. Aos 19 anos se tornou mãe de uma menina, o que impulsionou sua luta por um mundo mais justo e mais igualitário para as mulheres negras. Em 2002 ingressou no curso de Ciências Sociais, na Pontifícia Universidade Católica do Rio de Janeiro - PUC/RJ e em 2016 concluiu o mestrado em Administração Pública na Universidade Federal Fluminense - UFF, com a defesa da dissertação UPP - A redução da favela a três letras: uma análise da política de segurança pública do Estado do Rio de Janeiro.

Sua atuação foi marcada pela luta pelos direitos humanos, especialmente contra os abusos policiais contra a população pobre e negra nos aglomerados urbanos. Como coordenadora da Comissão de Defesa dos Direitos Humanos e Cidadania da Assembleia Legislativa do Rio de Janeiro - Alerj, ao lado do então deputado estadual Marcelo Freixo, trabalhou apurando denúncias tanto de policiais quanto de vítimas civis. Marielle também criticava duramente a intervenção federal no Rio de Janeiro, estabelecida por meio do Decreto n. ${ }^{\circ}$ 9.288, de 16 de fevereiro de 2018.

Oito meses após o seu atentado, que deixou órfã sua filha de 19 anos, e viúva a sua companheira, com quem vivia há cerca de um ano, não há muito o que os órgãos de investigação revelaram sobre o crime. Em uma das últimas declarações oficiais sobre o caso, o Ministro da Segurança Pública, Raul Jungmann, em entrevista ao site G1, do Portal Globo, afirmou no dia 22 de novembro de 2018 que um "complô" tem impedido a devida apuração do crime e que interesses que envolvem agentes públicos, milícias, políticos, não querem e impedem que se 
chegue aos mandantes do crime. ${ }^{4}$ Em outra reportagem, publicada no dia anterior, o Secretário de Segurança do Rio de Janeiro, general Richard Nunes, afirmou ter certeza que milicianos estão envolvidos com o mando ou a execução do assassinato de Marielle. Ele afirmava que o crime tem relação com a atuação política, e certamente com o envolvimento de milícias, no mando, ou na sua execução. ${ }^{5}$ Os dados do inquérito que apura as mortes foram proibidos de ser divulgados pela Rede Globo, que teve acesso ao documento no dia 14 de novembro, em decisão da Quarta Vara Criminal do Rio de Janeiro, que atendeu ao pedido da Divisão de Homicídios da Polícia Civil e do Ministério Público do estado.

Em março de 2019 o Policial Militar reformado Ronnie Lessa e o ex-Policial Militar Élcio Queiroz foram presos acusados de participarem da morte da vereadora e de seu motorista. Ronnie Lessa foi apontado como autor dos disparos. Ambos são suspeitos de integrarem uma organização paramiliar. ${ }^{6}$

Marielle foi eleita no pleito de 2016 com 46.502 votos, tornandose a $5^{\underline{a}}$ parlamentar mais votada no estado do Rio de Janeiro e a segunda mulher mais votada ao cargo de vereadora em todo o país (CARIELLO; ROMEO, 2018). Mas representava muito mais do que esses dados poderiam expressar. Marielle deu voz e corpo à população negra, silenciada nos espaços públicos e institucionais de poder e, especialmente,

\footnotetext{
${ }^{4}$ Vide: Ministro diz que 'complô' atrapalha investigação da morte de Marielle Franco. Distrito Federal. 22 de nov. de 2018. Disponível em <https://g1.globo.com/df/distrito-federal/noticia/2018/11/22/ministro-diz-que-comploatrapalha-investigacao-da-morte-de-marielle-franco.ghtml>. Acesso em 14 de jan. de 2019.

${ }^{5}$ Vide: Justiça proíbe TV Globo de divulgar conteúdo do inquérito que apura os assassinatos de Marielle e Anderson. Rio de Janeiro. 17 de nov. de 2018. Disponível em $<$ https://g1.globo.com/rj/rio-de-janeiro/noticia/2018/11/17/justica-proibe-tv-globo-dedivulgar-conteudo-do-inquerito-que-apura-os-assassinatos-de-marielle-eanderson.ghtml>. Acesso em 14 de jan. de 2019.

${ }^{6}$ Essas são as últimas atualizações informações sobre as investigações do crime que foram divulgadas até o fechamento dessa edição.
} 
o lado mais subalternizado dessa população: as mulheres negras. Como aquela que ousou falar, Marielle foi brutalmente silenciada. Mas as vozes das mulheres negras não cessaram de ecoar, e buscam o espaço institucional da política partidária como lugar de luta por representatividade, reconhecimento e igualdade.

Nesse contexto, reconhecemos muitas das candidaturas de mulheres negras nas eleições de 2018 como parte de um projeto coletivo, amplo e contínuo de emancipação e transformação social que tem orientado há algumas décadas as experiências de organização e de resistência das dessas mulheres. A partir dessa premissa, apresentaremos uma breve revisão bibliográfica da literatura sobre o feminismo negro pra então conhecer, elencar e interpretar, a partir dessa revisão, as ações de campanha de candidatas negras que aderiram a uma proposta de coletivização dos mandatos nas eleições proporcionais de 2018.

\section{Sob a Lei dos homens}

Em 2019, o Brasil apresenta 51\% a mais de mulheres na Câmara dos Deputados, se considerarmos o número de mulheres eleitas para essa casa legislativa para a legislatura de 2014-2018. De 51 cadeiras ocupadas por mulheres, passamos à 77. No Senado o número se manteve: em um total de 54 eleitos, sete são mulheres, segundo os dados do Repositório eleitoral do Tribunal Superior Eleitoral - TSE (2018).

O número de mulheres eleitas em 2018 para a Câmara é, por um lado, motivo para celebramos e, por outro, denuncia mais uma vez a gigantesca desigualdade de gênero que permeia os centros institucionais do poder político brasileiro. Somando-se as duas casas legislativas, Câmara e Senado, temos 567 vagas que serão ocupadas por apenas 84 mulheres na próxima legislatura. As mulheres são, no entanto, a maioria 
do eleitorado - 51,9\%, e quase a metade dos filiados a partidos políticos 44,3\% (TSE, 2018).

Esse cenário nos revela que a disputa político-partidária - esse espaço público que ainda é reconhecido como locus masculino no Brasil é um ambiente árido e hostil à concorrência feminina, prejudicando seriamente a representatividade desse segmento nas esferas institucionalizadas de disputa de agenda e poder políticos. Quando agregamos a raça ao gênero, o abismo das desigualdades se apresenta ainda mais profundo. ${ }^{7}$

Nas eleições para a Câmara dos Deputados de 2018, o número de mulheres negras ${ }^{8}$ passou de 10 para 13 representantes. No Senado, duas candidatas eleitas se autodeclaram pardas, assim como 12 dos eleitos homens. Em relação à Câmara, foram eleitos 113 homens negros, um aumento de 20 representantes em relação a 2014 (TSE, 2018). No total, entre mulheres e homens negros, temos 140 representantes negros no Congresso Nacional, o que equivale a cerca de $25 \%$ do poder legislativo federal. Sem dúvida, esse número é um avanço em relação à 2014, quando quase $80 \%$ do Congresso Nacional era branco. Esse quadro, no geral, se repete nas casas parlamentares estaduais e municipais. Cabe ressaltar

\footnotetext{
${ }^{7}$ Nesse sentido vale ressaltar a eleição de Joenia Wapichana, pelo partido Rede do estado de Roraima, primeira mulher indígena eleita para o Congresso Nacional.

${ }^{8} \mathrm{Na}$ construção da categoria "negro" pelas ciências sociais, destaca-se o trabalho de Carlos Hasenbalg publicado pela primeira vez em 1979, que evidenciou, por meio de análises e testes estatísticos, que as chances de ascensão para os pretos e pardos são substantivamente inferiores àquelas experimentada pelos brancos. HASENBALG (2005) agrega as categorias há muito utilizadas pelas instituições de pesquisas demográficas "preto" e "pardo" e cria a categoria analítica dos "não-brancos", demonstrando a distância desse grupo em relação aos brancos no que tange aos aspectos da estratificação socioeconômica. As pesquisas quantitativas das décadas de 1970 e 1980 se coadunam com as demandas dos movimentos negros do período, que defendem uma sociedade multirracial e a exaltação das identidades raciais. Vale ainda ressaltar que Há outras dimensões a serem consideradas nas relações entre pardos e pretos. Ou, talvez renovando-se a questão, entre negros de pele clara e negros de pele escura. O mestiço é ainda conceito aberto e as mudanças na estratégia da luta antirracista demandam novas perspectivas teóricas. As identidades raciais, que já foram muito diluídas no Brasil, ganham cada vez mais contornos claros e, de uma sociedade que um dia desejou se crer racialmente homogênea, passamos a uma sociedade que desenha novas fronteiras raciais.
} 
ainda que, segundo dados do TSE, do total de 28,1 mil pessoas inscritas para concorrer aos cargos de deputado estadual, deputado federal, senador, governador e presidente, $46 \%$ são negros. Os brancos representam 53\%, os amarelos (com ascendência asiática) são o,6\% e os indígenas são o,5\% (Ibidem, 2018). Não custa lembrar também que, conforme os dados do último Censo do Instituto Brasileiro de Geografia e Estatística - IBGE (2010), somos uma população composta por 47,7\% de brancos, 7,6\% de pretos e 43,1\% de pardos, 1,1\% amarelos e $0,4 \%$ indígenas. As eleições legislativas, por serem eleições proporcionais, são o termômetro da representação no campo da política institucional, é no poder legislativo que, em tese, estarão representados e serão debatidos os interesses dos segmentos diversos da sociedade.

Das múltiplas análises valiosas que podem ser realizadas a partir desses dados, e que infelizmente não encontram espaço no presente trabalho, vale destacar que a representação eleita não necessariamente corresponde à representatividade de um determinado segmento social. $\mathrm{O}$ que equivale dizer que, a eleição de um homem negro, por exemplo, não implica a defesa de pautas étnico-raciais no parlamento. Nesse sentido, as candidaturas negras e femininas formam um diferencial nas eleições 2018, já que a consciência e a afirmação de pertença racial e feminista são eixos da construção de suas agendas e de estratégias de campanha. As mulheres negras apontam novos caminhos para a política identitária, bem como traçam novas estratégias e formas de interação política em uma esfera tradicionalmente branca, rígida e patriarcal. ${ }^{9}$

\section{Os passos que vem de longe}

${ }^{9}$ É claro que isso não vale dizer que as candidaturas femininas negras são, necessariamente, representativas das demandas do feminismo negro. O que buscamos é destacar as candidaturas que se manifestam nesse sentido. 
A mulher negra quase sempre ocupa o papel de sujeito mais desfavorecido se levamos em consideração a maioria dos indicadores sociais brasileiros como acesso ao mercado de trabalho, acesso ao ensino superior em cursos de maior prestígio, acesso à saúde, entre outro, como aponta o Dossiê Mulheres Negras: retrato das condições de vida das mulheres negras no Brasil, desenvolvido pelo Instituto de Pesquisa Econômica Aplicada - IPEA (2013). As mulheres negras são ainda, segundo a pesquisa do IPEA, as mais vitimadas pela violência doméstica. A invisibilidade e a subalternidade da mulher negra, contudo, não alcançam apenas as suas condições materiais de existências, mas também a sua subjetividade e a sua cidadania (CARNEIRO, 2003).

Das ações de resistência à escravidão aos grupos feministas negros organizados, a luta da mulher negra contra o espaço social de subalternidade e invisibilidade a que foi submetida pelo racismo e pelo sexismo estruturantes das dinâmicas sociais brasileiras é longeva e ininterrupta. Contrastando com a sua participação político-partidária e institucional, a mulher negra hoje tem presença marcante nos movimentos sociais e nas entidades associativas, como associações de bairro, religiosas, sindicatos, culturais, ou mesmo dentro dos partidos políticos, embora poucas vezes ocupem os cargos eletivos (SEPPIR, 2015).

Werneck (2010), regatando a história brasileira e as mitologias em torno na formação da identidade feminina negra em organizações de resistência e em lugares de liderança afirma:

\footnotetext{
É possível encontrar em diferentes relatos sobre os quilombos no Brasil, ainda que de forma indireta, pistas da participação e liderança femininas em diferentes posições de comando, exemplificados pelas figuras de quilombolas como Aqualtune, Acotirene, Mariana Crioula, entre outras, ou de articulação econômica ou política de resistência. Nos dias atuais, existem ainda mais de quatro mil comunidades quilombolas em território nacional brasileiro, a que o Estado resiste em reconhecer e prover os direitos básicos de cidadania. Nestas comunidades, a liderança feminina não é incomum, a
} 
despeito do grau de penetração da cultura cristã em seu ambiente (Ibidem, p. 14-15).

Sobre o período pós-abolição, a autora recorda a fundação da primeira associação de empregadas domésticas, no estado de São Paulo, na década de 1930, sob a liderança da ativista Laudelina Campos Melo. Inauguravam-se no início do século XX novas formas de enfrentamento à exclusão da população negra e frentes que buscavam a garantia de participação na nova sociedade brasileira em desenvolvimento (WERNECK, 2010).

As mulheres negras que atuavam dentro dos movimentos organizados sejam os movimentos feministas, sejam os movimentos negros, precisaram sempre lutar pelo seu espaço: na condição de negras, em um espaço de feminismo majoritariamente branco, especialmente contra um ideal universal de mulher; e na condição de mulher, na luta contra o sexismo no bojo dos movimentos negros (GONZÁLEZ, 2011).

Assim, o movimento organizado de mulheres negras no Brasil se forma na década de 1970, em reação tanto às organizações feministas "tradicionais", que não contemplavam as pautas de reivindicação das mulheres negras, nem as incorporavam em um discurso majoritário que não contemplava as especificidades de suas experiências e histórias; como também aos movimentos negros organizados, permeados por discursos patriarcais e excludentes, que viam as questões de gênero postas pela militância feminina como de menor importância frente a questão racial ou como modos de "divisão frente ao inimigo maior: o mito da democracia racial brasileira" (VIANA, 2010, p. 56).

González (1982) marca o início desses movimento de mulheres, dentro do movimento negro carioca, no Rio de Janeiro a partir de 1974, quando aconteceram as "Semanas Afro-Brasileiras", entre 30 de maio a 23 de junho, com a participação de cerca de 6 mil pessoas. A partir desse evento, um grupo de militantes passou a se reunir semanalmente para a 
preparação de dois tipos de textos: um noticiário sobre racismo e atos de discriminação e o outro sobre história da África pré-colonial. Em razão de tensões e dificuldade de entendimento entre os as mulheres e aqueles que "se sentiam ameaçados pela capacidade e sensibilidade de suas colegas mais brilhantes" (Ibidem, p. 35), as mulheres passaram a ter um momento para se reunirem sozinhas, após as reuniões gerais. Em 1975, em evento feminista realizado para celebrar o Ano Internacional da Mulher, a partir do qual foi criado o "Centro da Mulher Brasileira" (CMB), as mulheres negras participantes divulgaram um documento em que denunciavam opressões próprias da sua condição racial, tal como a objetificação de seu corpo, como a erotização da "mulata tipo exportação" (VIANA, 2010). As mulheres negras começavam a buscar formas organizativas próprias no interior de suas entidades. Como afirmou Collins (2016), as mulheres ainda "têm sido empurradas por "sua marginalização em ambas as arenas" para criar o feminismo negro" (p. 99).

Em 1979, mulheres associadas ao Instituto de Pesquisa das Culturas Negras (IPCN) propõem "reunir mulheres que participavam ou tinham participado de várias entidades", tais como "organizações negras, das organizações de mulheres ou de outras organizações democráticas e progressistas", não para formar "mais um grupinho", e sim discutir uma "contra-ideologia" de combate ao racismo e o sexismo. Assim, conceberam o Reunião de Mulheres Negras Aqualtune (Remunea)" (VIANA, 2010, p. 57). No bojo do Movimento Negro Unificado, já haviam formado os Centros de Luta Maria Felipa e Luiza Mahin.

Em 1985 é realizado o III Encontro Feminista Latino-Americano, em Bertioga, São Paulo, quando a organização de mulheres negras com expressão coletiva emerge com política no campo feminista e o feminismo negro se ergue como força política identitária no Brasil (RIBEIRO, 2018). O I Encontro Nacional de Mulheres Negras é realizado em 1988, em Valença, interior do Rio de Janeiro, com a presença de 450 militantes de 17 
estados da federação. O segundo encontro, que aconteceu em Salvador, Bahia, em 1991, tinha por meta “a definição de um Projeto Político Nacional que respondesse a situação da mulher negra, levando em consideração a diversidade social, cultural e política da sociedade brasileira" (MOREIRA, 2006, p. 5).

O feminismo negro, além de trazer a questão racial para o centro do debate sobre as opressões, subverte algumas das demandas e categorias dos feminismos "tradicionais" (entendido em suas várias correntes) e propõe um debate sobre a possibilidade de atribuição de novos significados, como o próprio conceito de mulher, ou a ideia de que “o pessoal é político", lema da segunda onda feminista, especialmente no que toca à violência contra a mulher, bandeira feminista levantada nesse período. No feminismo negro, dizer que o pessoal é político significa

a compreensão de que o pessoal pode constituir-se em ponto de partida para a conexão entre politização e transformação da consciência. Logo não se trata de uma simples descrição da experiência de opressão de mulheres por homens mas do entendimento crítico sobre o terreno de onde essa realidade emerge (BAIRROS, 1995, p. 462).

A universalização do sentido da categoria mulher, construída inicialmente com base nas experiências de mulheres brancas e de classe média nas organizações feministas nacionais, também é posta em xeque pelo feminismo negro, bem como a defesa de outros parâmetros de feminilidade que os tradicionais. ${ }^{10}$ Pergunta Sojouner Truth ainda no século XIX." "Olhem para meus braços! Arei a terra, plantei, juntei a colheita nos celeiros, e nenhum homem podia se igualar a mim! E não sou

${ }^{10}$ Nesse mesmo sentido, Sueli Carneiro (2003) fala em enegrecer o feminismo, isto é, a necessidade de que as mulheres negras sejam representadas no bojo dos movimentos feministas.

${ }^{11}$ Discurso proferido por Sojourner Truth, ex-eacravizada, abolicionista e ativista pelos direitos das mulheres, em 1851, durante uma convenção em Akron, Ohio, Estados Unidos. 
eu uma mulher?". A mulher negra pleiteia ser reconhecida como sujeito, e ser sujeito de seu próprio discurso.

A partir do conceito lacaniano de "infante", González (2011) denuncia o silenciamento político e social da mulher negra nos espaços públicos e políticos:

O conceito de infante se constitui a partir de uma análise da formação psíquica da criança que, ao ser falado pelos adultos na terceira pessoa, é, consequentemente, excluída, ignorada, colocada como ausente apesar da sua presença; reproduz então esse discurso e fala em si em terceira pessoa (até o momento em que aprende a trocar os pronomes pessoais). Da mesma forma, nós mulheres e não-brancas, fomos "faladas", definidas e classificadas por um sistema ideológico de dominação que nos infantiliza. Ao impormos um lugar inferior no interior da sua hierarquia (apoiadas nas nossas condições biológicas de sexo e raça), suprime nossa humanidade justamente porque nos nega o direito de ser sujeitos não só do nosso próprio discurso, senão da nossa própria história. É desnecessário dizer que com todas essas características, nos estamos referindo ao sistema patriarcalracista (Ibidem, p. 13-14).

Nesse sentido, afirma Sueli Carneiro (2003) que o feminismo politiza as desigualdades de gênero transformando as mulheres em sujeitos políticos. E a partir dessa condição politizada, os sujeitos desencadeiam olhares diversos sobre processos particulares, ${ }^{12}$ do ponto de vista dos lugares sociais em que se encontram inseridos, como a condição social de mulher negra.

Collins (2016) já nos chamava a atenção para esse ponto de vista peculiar da mulher negra, que a permite realizar "análises distintas quanto às questões de raça, classe e gênero" (p. 99). Esse status, que a

${ }^{12}$ É importante ressaltar que as relações de raça, classe e gênero aparecem nos discursos feministas negros antes mesmo que a interseccionalidade fosse difundida como categoria analítica(principalmente a partir das análises de Crenshaw, na década de 1990). Nas décadas de 1970 e 80 a temática está presente nos textos de Angela Davis, Audre Lorde e Lélia González, por exemplo. No Brasil, Lélia Gonzalez dá especial atenção sobre as condições educacionais e de trabalho das mulheres negras e na negativa representação cultural da mulher negra. 
socióloga chama de outsider within é o olhar original e único daquela que está, ao mesmo tempo, dentro e fora da situação que vivencia/observa e ressalta o potencial criativo desse olhar. Em uma percepção muito apurada, Collins (2016) em uma afirmação aparentemente simples, ou mesmo óbvia- "o pensamento feminista negro consiste em ideias produzidas por mulheres negras que elucidam um ponto de vista de e para mulheres negras" (p. 101) - chama a atenção para os significados desse olhar, bem como para as potencialidades de suas realizações práticas.

Entendendo a política institucional como uma arena que pode ser disputada pelo feminismo negro, os novos modos de fazer política, ou mesmo as novas definições de política que podem ser gerados da prática, estão necessariamente em relação com o fato de a mulher negra estar ocupando esses espaços. Isso significa dizer que os novos arranjos políticos presentes nessas campanhas são, de fato, uma nova linguagem, que parte desse lugar específico de outsider within. E ao assumir esse lugar, a mulher negra tem condição de assumir as regras dos processos que Collins (2016) chama de autodefinição e de autoavaliação, que seriam um passo de grande relevância para movimentos de emancipação:

Quando mulheres negras definem a si próprias, claramente rejeitam a suposição irrefletida de que aqueles que estão em posições de se arrogarem a autoridade de descreverem e analisarem a realidade têm o direito de estarem nessas posições. Independentemente do conteúdo de fato das autodefinições de mulheres negras, o ato de insistir na autodefinição dessas mulheres valida o poder de mulheres negras enquanto sujeitos humanos (...) Enquanto a autodefinição de mulheres negras dialoga com a dinâmica do poder envolvida no ato de se definir imagens do self e da comunidade, o tema da autoavaliação das mulheres negras trata do conteúdo de fato dessas autodefinições (Ibidem, p. 103-104).

Podemos afirmar que autodefinição e autoavaliação são processos que percebemos nas últimas candidaturas femininas negras. Como afirma 
LORDE (1984), “la autodeterminación, la decisión de definirnos a nosotras mismas, de nombrarnos, de hablar por nosotras en vez de ser nombradas y expresadas por outros", ${ }^{13}$ este ato que parece estar "cheio de perigos" é, em realidade, um ato de libertação. A partir desse olhar as pautas antirracistas e a consciência de uma identidade interseccional vão construindo as demandas políticas das mulheres negras nos mais variados contextos. E tendo por horizonte a construção de uma sociedade antirracista e antissexista, o movimento de mulheres negras transcende essas mesmas questões, ampliando sua plataforma de ações, que passam por temas como a crítica à ordem neoliberal, a denúncia do encarceramento em massa, direitos reprodutivos, cultura do estupro e genocídio negro, por exemplo (RIBEIRO, 2018). Trata-se da ação de fala, em contra posição ao silêncio que, nos alerta LORDE (1984), não nos protege:

Pero en principio, para todas nosotras, es necesario enseñar con la vida y con las palabras esas verdades que creemos y que conocemos más allá del entendimiento. Porque sólo así sobreviviremos, participando en un proceso de vida creativo, contínuo y en crecimiento (Ibidem, n.p.). ${ }^{14}$

As ações políticas podem assim ser percebidas também como ato de libertação subjetiva e a esfera pública surge como espaço de novas narrativas postas em disputas por essas mulheres.

Phillips (2001) discute se os nossos interesses são mais bem projetivos se representados por aqueles que compartilham nossas experiências ou interesses, ou se melhor seria escolher representantes

13 "A autodeterminação, a decisão de definirmos a nós mesmas, de nos nomearmos, de falar por nós mesmas, em vez se sermos nomeadas e expressadas pelos outros" (tradução livre).

14 “Mas em princípio, para todas nós, é necessário ensinar com a vida e com as palavras essas verdades em que cremos e que conhecemos mais além do entendimento. Porque só assim sobreviveremos, participando em um processo de vida criativo, contínuo e em crescimento" (tradução livre). 
com bases em crenças e opiniões compartilhadas. Trata-se aqui da distinção entre a "política de presença" e "política de interesse" nos debates sobre as democracias representativas modernas. Segundo a autora, em que pese os argumentos que defendam que a política se faz através da disputa de interesses - e, nesse sentido, pouco importa quem representa esses interesses - em realidade, "uma vez que a diferença seja concebida em relação àquelas experiências e identidades que podem constituir diferentes tipos de grupos, fica bem mais difícil satisfazer demandas por inclusão política sem também incluir os membros de tais grupos” (PHILLIPS, 2001, p. 273 ). A “política de presença” pode conceder um peso significativamente maior à diferença de grupo do que a política de ideias admite.

A representatividade política e a ocupação dos espaços de poder são vitais, portanto, para o alcance dos objetivos do feminismo negro, que tem por horizonte uma transformação social radical. "A conquista da representação no campo político é uma possibilidade para que então as feministas negras formulem políticas que atendam às suas demandas”, afirma Moreira (2006, p. 6). E ação coletiva é o meio eleito pelas mulheres negras para o empoderamento e o enfrentamento dos desafios impostos pelas instituições e pela sociedade.

\section{Mulher Negra, substantivo coletivo}

Segundo Ribeiro (2018), o empoderamento postulado pelas mulheres negras não é uma tomada de poder pessoal ou subjetiva, mas uma ação coletiva capaz de colocar as mulheres como sujeitos ativos da mudança na luta pela equidade: "é uma nova concepção de poder que produz resultados democráticos e coletivos”, afirma a autora (Ibidem, p. 1628). 
É por essa chave interpretativa que podemos enxergar a dinâmica e as estratégias eleitorais das mulheres negras nas eleições aos cargos proporcionais em 2018: um movimento solidário, coletivo e contínuo, ao mesmo tempo seguindo as pegadas de Marielle Franco e fazendo parte de um longo caminho que a antecede. Marielle, como mulher negra na luta política, não era só sujeito, era coletivo, pois assim tem sido construídas as lutas e conquistas das mulheres negras no plano político.

As eleições de 2018 experienciam uma nova forma de concorrência através das candidaturas coletivas de mulheres negras e das campanhas organizadas em torno de candidaturas negras. A motivação de candidaturas em razão de uma questão identitária de raça/cor não é exatamente uma novidade. Em 1954, Abdias do Nascimento foi candidato a verdeador na cidade do Rio de Janeiro com o slogan "não vote em branco, vote no preto". Mas, apesar da atuação político-partidária ter sido incentivada pelo Teatro Experimental do Negro - $\mathrm{TEN}^{15}$ no breve período democrático anterior ao golpe de 1964, não houve um movimento coletivo amplo e difuso em torno dessa ou de outras candidaturas, tampouco foram postas em prática estratégias inéditas e coletivas para significar e impulsionar as campanhas, como foi o caso das eleições femininas de 2018.

Inspirada exatamente por essa candidatura de Abdias no Nascimento, Linda Marxs, colunista do blog Efigenias, criou na rede social Facebook o grupo "1 Milhão de Brancos Votando em Candidatos Pretos", para divulgar candidaturas negras e fazer campanha também junto à população branca:

O 1 Milhão de Brancos é uma reverberação do movimento Vote em Preto, com o objetivo de brincar e provocar, usando a linguagem do meme, para fazer emergir ideias e incentivar que as pessoas abandonem os clichês, como quem diz que não

\footnotetext{
${ }^{15}$ Movimento negro fundado em 1944 que tinha por objetivo o resgate da identidade negra e a sua valorização por meio da cultura e da arte, bem como a luta antirracista e a representatividade negra nos espaços públicos.
} 
considera o voto 'por cor' porque dá prioridade para a competência dos candidatos. Só que esse eleitor só vota em candidatos brancos e, ao mesmo tempo, diz que todas as pessoas são iguais. Então, essa provocação tem um tom de humor, mas também é uma forma real de angariar votos para os candidatos pretos (BELCHIOR, 2018, n.p).

Em julho de 2018 foi lançada pela pela Rede Umunna (rede de mulheres negras que pesquisam e promovem a presença de mulheres negras na política institucional) a plataforma digital "Mulheres Negras Decidem”, com o objetivo de criar um espaço para as mulheres negras se articularem, obter dados e informações sobre o sistema político e as candidaturas, auxiliando a luta das mulheres negras por representatividade política (MAGALHÃES, 2018, n.p).

No Rio de Janeiro foram eleitas em 2018 para a Câmara dos Deputados e para a Assembleia Legislativa do Estado (ALERJ) pelo PSOL quatro ex-assessoras de Marielle, todas mulheres negras e oriundas da periferia, além de novatas na linha de frente da política institucional: Renata Souza, Mônica Francisco e Daniela Monteiro (eleitas deputadas estaduais) e Talíria Petrone ${ }^{16}$ para a Câmara de Niterói. As quatro novas parlamentares que decidiram a candidatura no mesmo momento e afirmam ter se inspirado em Marielle, veem o seu mandato como a continuidade de um legado: "costumo dizer que o legado da Marielle não é o legado de uma pessoa, seria injusto com a história dela. É universal, é para a humanidade" (BETIM, 2018, n.p.).

Os movimentos mais inovadores e pioneiros de candidatura coletiva, predominantemente negra e feminista, contudo, aconteceram em Pernambuco e em Minas Gerais.

O coletivo "Juntas" (PSOL), formado por cinco mulheres (Robeyoncé Lima, Kátia Cunha, Jô Cavalcanti, Carolina Vergolino e

${ }^{16}$ Exerceu o mandato de vereadora pelo Partido Socialismo e Liberdade (PSOL) na Câmara Municipal de Niterói, de 2016 até o lançamento de sua candidatura à deputada estadual, em 2018. 
Joelma Carla) foi chapa eleita com mais de 39.000 votos para ocupar uma das 49 cadeiras da Assembleia Legislativa de Pernambuco (Alepe). Formalmente, quem irá ocupar o cargo de deputada estadual é Jô Cavalcanti, atualmente coordenadora nacional do Movimento dos Trabalhadores e Trabalhadoras Sem Teto (MTST), mas ela garante que as decisões serão tomadas em conjunto, não só entre as cinco que compõe o Juntas, mas também pelo conselho político que será formado com membros da sociedade civil.

No mandato, que é chamado de "mandata", elas se dividem nas áreas de comunicação, mobilização, jurídica e pesquisa para garantir que as propostas do coletivo cheguem ao parlatório da Casa. A gota d'água para a candidatura coletiva, informa Carolina Vergolino, foi o assassinato da vereadora Marielle Franco. Ao longo da campanha o Juntas se apresentou como grupo e, embora um único rosto fosse estampado nas urnas, nas ruas, no site do coletivo e nas suas mensagens de campanha, todas as cinco eram apresentadas. (ROSSI, 2018).

Já em Minas Gerais, a própria campanha foi marcada pela solidariedade entre as mulheres, mesmo se elas não formassem expressamente uma candidatura coletiva:

Em vídeo, várias candidatas pediam voto para as colegas. "Eu sou Áurea Carolina, candidata a vereadora. Mas se você não quiser votar em mim, vote na Polly". Polly então aparecia dizendo "a Cristal também tem propostas ótimas, vote nela". E Cristal defendia o voto em outra companheira de partido. Assim uma candidata ia reforçando a candidatura da outra. (PORTELA, 2018, n.p).

Essa relação solidária entre as mulheres candidatas teve início em 2015, quando integrantes de movimentos, organizações, coletivos e ativistas independentes de Belo Horizonte criaram o movimento “MUITAS”, e em 2016 formaram a Frente de Esquerda BH Socialista (PSOL, PCB, Brigadas Populares e MLB) lançando a candidatura de mulheres 
para disputar vagas na Câmara Municipal de Belo Horizonte sob o lema "votou em uma, votou em todas". Foram eleitas Áurea Carolina e Cida Falabella, ambas pelo PSOL, sendo que Áurea, mulher negra, foi a vereadora mais votada da história da cidade.

A partir desse movimento desenhou-se um mandato coletivo formado pelas duas vereadoras, mais Bella Gonçalves, a terceira mais votada da coligação, que passaram a trabalhar com uma equipe única, estratégias compartilhadas, posicionamentos coletivos e um gabinete comum - as paredes dos gabinetes foram, inclusive, fisicamente derrubadas - em um sistema de co-vereança. As candidaturas pactuaram princípios comuns, como a redução de privilégios, a radicalização democrática e a representatividade de gênero e étnico-racial, e a Gabinetona, o nome dado a esse arranjo e pelo qual ele é reconhecido, foi composta majoritariamente por mulheres negras.

A experiência de 2016 e a Gabinetona foram certamente inspiração para as campanhas de 2018. Áurea Carolina foi eleita deputada federal por Minas Gerais, e pretende levar a condução coletiva do mandato para a Câmara federal.

É importante aqui fazer duas ressalvas. A primeira é sobre a singularidade da experiência da Gabinetona. Em Alto Paraíso de Goiás, no interior do Estado, um grupo de cinco pessoas se propôs a exercer um mandato coletivo em a partir da eleição do advogado João Yuji (Partido Trabalhista Nacional - PTN) para vereador, em 2016. Assim, embora a experiência de mandato coletivo da Gabinetona não tenha sido a única do período, ela certamente é marcada por sua especificidade. A começar por seus objetivos e motivações. O grupo encabeçado por Yuji tinha como propósito a descentralização política e a transformação da democracia representativa em "participativa" (CARAZZAI, 2016). A Gabinetona, embora também se filie a esse ideal, tinha por objetivo compartilhar mandatos eleitos, dentro e fora da Câmara, bem como era orientada por 
um fazer feminista e racialmente identitário, que pautava não só o seu agir, mas o seu pensar, propor e decidir políticos. E, embora na Gabinetona - e em outros movimentos de solidariedade feminina nas campanhas, e essa é a segunda ressalva - tenham como participantes mulheres brancas, esses são, de fato, movimentos majoritariamente negros, pautados por experiências e princípios norteadores dos movimentos feministas negros.

Não é coincidência que sejam as mulheres negras os principais rostos, mentes e mãos das mais variadas campanhas solidárias, sites de divulgação, páginas de redes sociais e candidatas a eleições em articulações de dinâmicas coletivas. Collins (2016) destaca a noção de sisterhood (irmandade), o sentimento solidário de lealdade e ligação com outras mulheres, decorrente de um sentimento compartilhado de opressão, como elemento fundamental da cultura das mulheres negras. Tampouco é o acaso que fez com que a frase "Marielle virou semente" se tornasse lema de quase a totalidade dessas campanhas.

\section{"Falando a voz de nossos desejos"17}

As disputas das mulheres negras, seja no campo da política, seja em outros campos sociais, têm sido realizadas sob condições de intensa desigualdade e opressão. São necessárias estratégias cotidianas de enfrentamento e sobrevivência que deem conta de que as mulheres negras nos coloquemos em movimento de desenvolvimento e transformação, sem que se perca a voz própria. A experiência de emancipação da mulher negra, que desafia diretamente a sociedade sexista, classista e racista, molda de certa maneira a sua percepção e a sua ação no mundo, marcadas pela identidade e ancestralidade:

\footnotetext{
${ }^{17}$ Werneck, 2010, p. 16.
} 
Essa experiência pode moldar nossa consciência de tal maneira que nossa visão de mundo seja diferente da de quem tem um grau de privilégio (mesmo que relativo, dentro do sistema existente). É essencial para a continuação da luta feminista que as mulheres negras reconheçam o ponto de vista especial que a nossa marginalidade nos dá e façam uso dessa perspectiva para criticar a hegemonia racista, classista e sexista dominante e vislumbrar e criar uma contra-hegemonia (HOOKS, 2015, p. 197).

As eleições de 2018 nos mostraram, na prática, esses pontos de vistas, bem como foram o momento do desenvolvimento de novas estratégias de ingresso no enrijecido sistema político-eleitoral brasileiro. E tais estratégias se valeram de dinâmicas políticas solidárias, que romperam com a valorização exacerbada do pessoalismo e do individualismo, ao mesmo tempo em que indagam "a partir de qual ou quais formas poderemos, radicalizando os princípios das ialodês ou os princípios feministas e suas contradições, nos colocar na arena pública em nosso próprio nome" (WERNECK, 2010, p. 16).

Ecoar Marielle significa entender essas candidaturas como representação dessa luta contínua, ainda que cada uma dessas mulheres eleitas apresente também suas pautas e visões de mundo singulares. Mas o aspecto da representatividade feminina negra não sai do horizonte: a mulher negra e as pautas do feminismo negro no poder, enfim, passam a projeto. Como diz Angela Davis: são as mulheres negras na construção de uma nova utopia.

\section{REFERÊNCIAS}

BAIRROS, Luiza. Nossos Feminismos revisitados. Revistas Estudos Feministas. Florianópolis, n. 2, p. 458-463, 1995.

BELCHIOR, N. Iniciativas cidadãs incentivam o voto em candidatos negros. Carta Capital, São Paulo, 5 de out. de 2018. Disponível em $<$ http://negrobelchior.cartacapital.com.br/iniciativas-cidadas- 
incentivam-o-voto-em-candidatos-negros/>. Acesso em 30 de nov. de 2018.

BETIM, Felipe. As 'outras' Marielles que o Rio elegeu. El País, Rio de Janeiro, 12 de out. de 2018. Disponível em <https://brasil.elpais.com/brasil/2018/10/11/politica/1539275009_606211.ht $\mathrm{ml}>$. Acesso em 30 de nov. de 2018.

CARAZZAI, Estelita Hass. Grupo é eleito para 'mandato coletivo' de vereador em Goiás. Folha de São Paulo, Curitiba, 12 de out. de 2016. Disponível em <https://www1.folha.uol.com.br/poder/eleicoes2016/2016/10/1822231-grupo-e-eleito-para-mandato-coletivo-de-vereadorem-goias.shtml>. Acesso em 30 de nov. de 2018.

CARIELO, Gabriel; ROMEO, Madalena. Marielle Franco: Negra, moradora da Maré e a quinta vereadora mais votada do Rio. O Globo, Rio de Janeiro, 14 de mar. de 2018. Disponível em $<$ https://oglobo.globo.com/rio/marielle-franco-negra-moradora-damare-a-quinta-vereadora-mais-votada-do-rio-22491120>. Acesso em 30 de nov. de 2018.

CARNEIRO, Sueli. Mulheres em movimento. Estudos Avançados, São Paulo , v. 17, n. 49, p. 117-133, Dec. 2003. Disponível em $<$ http://www.scielo.br/scielo.php?script=sci_arttext\&pid=So10340142003000300008\&lng=en\&nrm=iso $>$. Accesso em 30 de nov. de 2018.

COLLINS, Patricia H. Aprendendo com a outsider within: a significação sociológica do pensamento feminista negro. Revista Sociedade e Estado, v. 31, n. 1, p. 99-127, jan/abr., 2016.

GONZÁLEZ, Lélia. Por um feminismo Afro-latino-americano. Caderno de Formação Política do Círculo Palmarino, n.1, Batalha de Ideias: AfroLatinoAmérica, p. 12-21, 2011.

.; HASENBALG, Carlos. Lugar de Negro. Coleção 2 Pontos, v. 3. Rio de Janeiro: Marco Zero, 1982.

HOOKS, Bell. Mulheres negras: moldando a teoria feminista. Revista Brasileira de Ciência Política, n. 16, p. 193-210, jan/abr., 2015.

IPEA - Instituto de Pesquisa Econômica Aplicada. Dossiê Mulheres Negras: retrato das condições de vida das mulheres negras no Brasil. Brasília: Ipea, 2013. 
LORDE, Audre. La transformación del silencio en lenguaje y en acción. In: . Hermana Marginada (Sister Outsider). Ensayos y Conferencias.

The Crossing Press/Feminist Series, 1984.

MAGALHÃES, Sabrina. Plataforma 'Mulheres Negras Decidem' lançada em apoio à representatividade da mulher negra na Política. Combate ao Racimo Ambiental, Rio de Janeiro, 28 de jul. de 2018. Disponível em https://racismoambiental.net.br/2018/o7/28/plataforma-mulheresnegras-decidem-lancada-em-apoio-a-representatividade-da-mulhernegra-na-politica-video/>. Acesso em 21 de dez. de 2018.

MOREIRA, Núbia. Representação e identidade no feminismo negro brasileiro. In: Seminário Internacional Fazendo Gênero 7, 2006. Florianópolis: Ed. Mulheres, 2006.

PHILLIPS, Anne. De uma política de idéia de uma política de ideias a uma política de presença?. Estudos Feministas, Florianópolis, ano 9, p. 268290, 2001.

PORTELA, Laércio. Elas vão juntas: cinco candidatas e um único número na urna. Jornal GNN, 12 de jun. de 2018. Disponível em <https://jornalggn.com.br/blog/marco-zero/elas-vao-juntas-cincocandidatas-e-um-unico-numero-na-urna>. Acesso em 15 de nov. de 2018.

RIBEIRO, Djamila. Quem tem medo do feminismo negro?. São Paulo: Companhia das Letras, 2018. [Versão Kindle].

ROSSI, Marina. “Quando dizem que Marielle virou semente, é muito real”. El País, Recife, 12 de out. de 2018. Disponível em $<$ https://brasil.elpais.com/brasil/2018/10/12/politica/1539356144_236403.h tml>. Acesso em 20 de nov. de 2018.

SEPPIR-Secretaria Nacional de Políticas de Promoção da Igualdade Racial. A participação das mulheres negras nos espaços de poder. Brasília, 2015. Disponível em <http://www.seppir.gov.br/central-deconteudos/publicacoes/pub-acoes-afirmativas/a-participacao-dasmulheres-negras-nos-espacos-de-poder>. Acesso em 23 de nov. de 2018.

TSE-TRIBUNAL SUPERIOR ELEITORAL. Repositório de dados eleitorais. Disponível em $<$ http://www.tse.jus.br/eleicoes/estatisticas/repositorio-de-dadoseleitorais-1/repositorio-de-dados-eleitorais>. Acesso em 12 de dez. de 2018. 
VIANA, Elizabeth E. S.. "Lélia Gonzalez e outras mulheres: Pensamento feminista negro, antirracismo e antissexismo". Revista da ABPN, v. 1, n. 1, p. 52-63, mar/jun ,2010.

WERNECK, Jurema. Nossos passos vêm de longe! Movimentos de mulheres negras e estratégias políticas contra o sexismo e o racismo. Revista da ABPN, [S.1.], v. 1, n. 1, p. 07-17, jun., 2010. ISSN 2177 Disponível em:<http://abpnrevista.org.br/revista/index.php/revistaabpnı/article/vie w/303>. Acesso em: 25 dez. 2018. 